\title{
The effect of a new communication template on anticipated willingness to initiate or resume allergen immunotherapy: an internet-based patient survey
}

Moises A. Calderon ${ }^{1 *}$, Linda Cox ${ }^{2}$, Thomas B. Casale ${ }^{3}$, Ralph Mösges ${ }^{4}$, Oliver Pfaarr, ${ }^{5,6}$, Hans-Jørgen Malling ${ }^{7}$, Joaquin Sastre ${ }^{8}$, Musa Khaitov ${ }^{9}$ and Pascal Demoly ${ }^{10,11}$

\begin{abstract}
Background: A patient's knowledge of his/her allergic condition and treatment is a key factor in adherence and effectiveness.

Methods: To assess patients' understanding of allergy and acceptance of allergen immunotherapy on the basis of (i) information given by their physician at the time of prescription and (ii) a new communication template viewed some months later, we performed an Internet-based survey of patient panels in France, Germany, Spain, the USA and Russia. The survey participants were either recent "early abandoners" (having discontinued allergen immunotherapy before the end of the prescribed course) or "non-starters" (having decided not to initiate a course of allergen immunotherapy recommended by their physician). All participants completed an on-line questionnaire immediately before and immediately after viewing the new communication template. The study's main objectives were to validate the new communication template and to assess its impact on anticipated willingness to initiate or resume allergen immunotherapy.
\end{abstract}

Results: We surveyed a total of 261 patients (France: 57; Germany: 51; Spain: 52; USA: 51; Russia: 50), comprising 127 "early abandoners" and 134 "non-starters". The mean time since symptom onset and selection for the study was 14.5 years. Subcutaneous allergen immunotherapy had been prescribed in $60 \%$ of cases. Twenty-eight percent of the participants did not know for which allergy they were being treated. Early abandoners reported a perception of low effectiveness (39\%) and complained about expense (39\%) and practical constraints (32\%). Twenty-two percent of the non-starters feared side effects. The communication template was considered to be clear (by $92 \%$ of the patients), convincing (by $75 \%$ ) and reassuring (by $89 \%$ ); $80 \%$ of the participants felt better informed afterwards, and $67 \%$ stated that viewing the communication template would have made them more likely to continue or initiate allergen immunotherapy (overall willingness score: 5.65 out of 10 before viewing and 7.1 out of 10 afterwards).

Conclusions: After viewing a new communication template on allergy and allergen immunotherapy, patients participating in the survey felt better informed and more likely to initiate or complete this therapy. It now remains to investigate the communication template's effect on actual acceptance of and adherence to allergen immunotherapy.

Keywords: Allergen immunotherapy, Allergy, Adherence, Information, Patient-physician communication

\footnotetext{
* Correspondence: m.calderon@imperial.ac.uk

'Section of Allergy and Clinical Immunology, Imperial College London -

National Heart \& Lung Institute, Royal Brompton Hospital, Dovehouse Street,

London, United Kingdom

Full list of author information is available at the end of the article
}

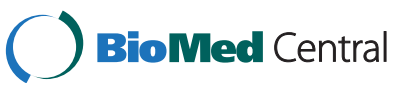

(c) 2015 Calderon et al.; licensee BioMed Central. This is an Open Access article distributed under the terms of the Creative Commons Attribution License (http://creativecommons.org/licenses/by/4.0), which permits unrestricted use, distribution, and reproduction in any medium, provided the original work is properly credited. The Creative Commons Public Domain Dedication waiver (http://creativecommons.org/publicdomain/zero/1.0/) applies to the data made available in this article, unless otherwise stated. 


\section{Background}

Allergic rhinitis (AR) is a chronic, immunoglobulin E (IgE)-mediated inflammatory disease of the upper airways that affects a signification proportion of adult and paediatric populations worldwide [1-3]. According to a recent review, the patient-reported prevalence of the symptoms of AR is $7.2-54.1 \%$ in Africa, $5.5-45.1 \%$ in Latin America, 12-30 \% in North America, 23-30 \% in Europe and $18.2 \%$ in the Russian Federation $[4,5]$, although physician-diagnosed prevalences are lower. Furthermore, AR is a known risk factor for the development of allergic asthma [6]. The condition has a considerable socioeconomic burden and impairs health-related quality of life $[7,8]$. Although most cases of AR are treated with symptomatic drugs such as H1-histamine receptor antagonists and/or nasal corticosteroids [1-3], about $20 \%$ of patients do not achieve disease control [9].

According to most guidelines, allergen immunotherapy (AIT) is a treatment option for patients with moderateto-severe IgE-mediated respiratory allergies and in whom medications such as antihistamines and moderate-dose topical glucocorticoids provide insufficient symptom control [1, 2, 10-14]. AIT is an effective, disease-modifying treatment for AR [15-18]. Furthermore, a recent review found that 23 out of 24 health economics studies of AIT compellingly demonstrated the cost savings conferred by AIT over symptomatic drug treatment [19].

Although AIT starts to act on symptoms within a few weeks or months [20-22], courses of several years are needed to switch the immune system to a tolerogenic regulatory $\mathrm{T}$ cell profile and Th2 to Th1 immune rebalancing $[1,2,13,16,17]$. Good adherence to AIT is essential for effectiveness and comprises a series of components: initiation, implementation (also referred to as compliance) and discontinuation (the reciprocal of which is persistence). Adherence depends on several interacting factors, including inconvenience, cost factors, treatment benefit (or lack of, and as perceived by both patients and physicians) and the patient's level of knowledge about his/her allergic condition and treatment [23-29]. In the literature, the implementation/compliance component of adherence to AIT (defined as the percentage of prescribed medication actually taken by the patient) ranges from around $25 \%$ to over $90 \%$. These values come from studies that vary in terms of the patient population, allergen preparation, the administration route (subcutaneous or sublingual), the administration regimen (continuous or discontinuous), the frequency of administration and the overall treatment period (from several months to several years) [23, 2729]. Nevertheless, most reported values are between $60 \%$ and $80 \%$. In terms of the discontinuation component of AIT, Anolik et al.'s retrospective health record review found that $69 \%$ of 231 patients having discontinued
AIT before the end of the three-year treatment period did not have a specific, physician-recorded, reason for discontinuation (despite regular consultations during this period) or did not return to the office for further evaluation or treatment [30]. In a retrospective "real-life" review of a pharmacy database containing data on 6486 patients having initiated AIT with one or more of the allergens of interest between 1994 and 2009, Kiel et al. found that a specialist prescriber, single-allergen AIT, lower socioeconomic status and younger age were all independent predictors of premature discontinuation (i.e. poor persistence) [31]. One can speculate that use of single-allergen AIT to treat potentially polysensitized patients may have had a negative impact on adherence in Kiel et al.'s study. Overall, these results suggest that a factor broadly defined as "motivation" is important in adherence in general and persistence in particular.

The objective of the present international, observational, Internet-based survey was to assess patients' understanding of and commitment to AIT based on (i) the information provided during consultation with the prescribing physician and then (ii) following presentation of a new communication template about allergy and AIT. We focused solely on "non-starters" (i.e. patients who had elected not to initiate AIT, despite their physician's recommendation), and "early abandoners" (i.e. patients who had prematurely ceased a prescribed course of AIT). Furthermore, we measured the impact of a new communication template on the survey participants' willingness to start or resume treatment.

\section{Methods}

\section{Survey design and population}

We performed an observational, Internet-based survey in five countries around the world (France, Germany, Spain, the USA and Russia). These countries were selected to reflect markets in which AIT is well established (France, Spain, USA and Germany) and/or is likely to develop even further (Russia and the USA, where SLIT is currently being launched). In each country, we contacted members of patient panels previously constituted by market research organizations and invited them to participate in an Internet-based survey. In view of the observational, non-interventional nature of this Internetbased survey, specific ethical and regulatory approval was not required. The study therefore does not have a clinical trial number. The panel members had provided their general consent to participation in opinion surveys and subsequent exploitation of the collected data but had not provided individual consent to this survey. The participants were not necessarily being treated with AIT products from the study sponsors (Stallergenes SA, Antony, France, and ALK-Abelló A/S, Hørsholm Denmark). Participants screened themselves for eligibility 
(i.e. through self-reporting) with a short Internet questionnaire and were not examined by a physician as part of the selection process. The inclusion criteria were as follows: (i) age 18 or over, (ii) physician-diagnosed AR (regardless of the inducing allergen or time since diagnosis); (iii) moderate-to-severe nasal and ocular symptoms (self-reported); (iv) allergic symptoms for at least one month per year (self-reported); (v) a recommendation of AIT by the participant's physician (whether a specialist or a primary care physician) within the previous 12 months; (vi) recollection of the information about allergy and AIT given by the prescribing physician; and (vii) discontinuation of AIT before the end of the recommended course (for "early abandoners") or refusal to start a course of AIT (for "non-starters"). Approximately equal numbers of early abandoners and non-starters were recruited. Individuals intending to start AIT in the coming weeks or taking AIT at the time of the screening step were excluded from the survey. Lastly, people who had been told to discontinue AIT by a physician were excluded from the survey.

\section{The survey questionnaire}

Eligible participants filled out a 41-item, Internet-based questionnaire (developed by the panel of authors specifically for this survey: see the Additional file 1) in March and April 2014. The questionnaire was translated into local languages from English and then translated back into English for validation and cultural adaptation [32]. The questionnaire covered (i) the participant's allergies, symptoms and treatments, (ii) the participant's perception of the information on allergy and AIT provided by the physician at the time AIT was recommended, (iii) the participant's perception of the new communication template on allergy and AIT (see below), and (iv) willingness to start or resume AIT after having viewed a new communication template (see below). All questionnaire data were anonymous. No directly or indirectly nominative information was recorded. Some of the questions were open-ended. The Internet-based survey questionnaire took around $15 \mathrm{~min}$ to fill out.

\section{The new communication template}

The new communication template on allergy and AIT (Table 1) was developed (in English) in several rounds by drawing on the authors' personal experience and the scientific literature on the types and formats of health information preferred by patients and physicians [33]. The goal was to summarize information on the characteristics of allergic disease (in one section) and the features and mode of action of AIT (in another section) in concise, lay terms. Any disagreements were resolved by consensus. A draft template was tested in four countries (France, Germany, Russia and the USA) in the local language by presentation to a total of 445 physicians
Table 1 The new communication template on allergy and AIT About respiratory allergies

- Respiratory allergy results from a disorder of the immune system

- Respiratory allergy is a chronic disease caused by both a genetic predisposition and environmental factors. In predisposed persons, exposure to several factors (such as pollution, smoking, and climate change) can cause or exacerbate allergy.

- Respiratory allergy is a progressive disease that gradually worsens over time, with an increased risk of polysensitization and asthma

- Respiratory allergy has severe consequences:

- Direct disease burden: symptoms impair everyday activities and degrade the quality of sleep, inducing fatigue and impacting learning and attention.

- Impact on work/school performances: among chronic diseases, allergic rhinitis has the highest impact on productivity.

About allergy immunotherapy

Main definition of AIT:

Allergy immunotherapy (AIT) is the only allergy treatment with a longlasting effect on all symptoms.

AIT induces tolerance to allergens by rebalancing the immune system.

AIT is a targeted and efficient solution.

Key messages

- Which patients is AlT for?

- AIT is mainly dedicated to patients in whom symptomatic medications are insufficiently effective or poorly tolerated.

\section{- How does it work?}

- AIT is a targeted solution: After an accurate diagnosis, patients receive a tailored treatment.

- AIT is a disease-modifying allergy treatment that acts on the immune system itself by rebalancing it (in contrast to symptomatic drugs like antihistamines and corticoids, which only temporarily stop the symptoms of allergic reactions).

- There are several mode of administration: injections to be given monthly at the medical office or drops placed under the tongue, according to the preferences and needs of the patient. Tablets are available for grass pollen allergies.

- AIT is an efficient solution:

- Only one treatment active on all symptoms (in contrast to most of the antihistamines and corticoids that affect primarily nasal or eye symptoms).

- Efficacious over the long-term: Efficacy is sustained over successive years even after the treatment is stopped

- Reduces the use of symptomatic medication (antihistamines and/or corticoids).

(including general practitioners, allergy specialists and both AIT prescribers and non-prescribers), pharmacists, and patients with respiratory allergies. The draft was 
then modified according to the feedback received. In the present study, the new communication template was presented to the survey participants immediately after they had completed the study questionnaire. Immediately after presentation of the new communication template, the study questionnaire was then administered again, in order to measure any changes in views and opinions.

\section{Data management}

A descriptive analysis of the survey data was performed with SPSS software (version 15.0.1, IBM Corporation, Armonk, USA). Quantitative parameters are expressed as the mean, and qualitative parameters are expressed at a percentage of the corresponding survey population or subpopulation.

\section{Results}

\section{Characteristics of the survey population (Table 2)}

A total of 261 eligible participants (France: $\mathrm{n}=57$; Germany: $\mathrm{n}=51$; Spain: $\mathrm{n}=52$; USA: $\mathrm{n}=51$; Russia: $\mathrm{n}$ $=50$ ) were included in the Internet-based survey and filled out the survey questionnaire (Fig. 1). For the population as a whole, the mean time between the onset of allergic symptoms and inclusion in the survey was 14.5 years. During this time, the participants had been treated with a range of symptomatic medications and (for early abandoners) AIT. There were 134 non-starters (France: $\mathrm{n}=32$; Germany: $\mathrm{n}=26$; Spain: $\mathrm{n}=26$; USA: $\mathrm{n}=25$; Russia: $\mathrm{n}=25$ ) and 127 early abandoners (France: $\mathrm{n}=25$; Germany: $\mathrm{n}=25$; Spain: $\mathrm{n}=26$; USA: $\mathrm{n}=26$; Russia: $\mathrm{n}=25$ ). The nonstarters were more likely to be consulting a primary care physician (relative to early abandoners).

Unfortunately, precise data on the duration of AIT in early abandoners were not available. However, the great majority (79 \%) of the early abandoners had discontinued AIT after several months (rather than a few days). The proportion of early abandoners having discontinued AIT after several months (rather than a few days) differed markedly from one country to another (France: 60 \%; Germany: 100 \%; Spain: 81 \%; USA: 85 \%; Russia: $68 \%)$. Although data on allergen sensitization were not available, the triggering allergens most frequently reported by the participants were grass pollen $(78 \%)$, tree pollen (67\%), house dust mites (53\%) and animal dander (40\%) (Table 2).

The proportion of participants reporting that AR had a moderate-to-severe impact on their personal life ranged from $76 \%$ to $100 \%$, depending on the country and the subgroup (Table 2). The corresponding values for the impact on professional life were only slightly lower (38 \% to $92 \%$; Table 2). Concomitant asthma (though not necessarily allergic) was reported by $27 \%$ of the participants. Non-starters were more likely than early abandoners to report that their main physician in the treatment of their allergy was a primary care physician (rather than a specialist).

\section{The prescribed course of AIT and reasons for non-initiation or discontinuation of treatment (Table 3)}

Overall, SCIT had been prescribed in $60 \%$ of cases (in $57 \%$ of early abandoners and $62 \%$ of non-starters). The proportion of participants prescribed with SCIT was higher in Germany, the USA and Russia (over $60 \%$ ) than in France and Spain (below 40 \%) (Table 3). Overall, $41 \%$ of the administration regimens were continuous (i.e. year-round), $53 \%$ were discontinuous (e.g. pre- and co-seasonal or co-seasonal only, for intermittent allergies) and $5 \%$ were not specified.

Strikingly, $28 \%$ of the survey participants did not know with which allergen they were being treated (France: 46 \%; Germany: 18 \%; Spain: 29 \%; USA: 20 \%; Russia: $24 \%)$. Unsurprisingly, this percentage was higher in non-starters (34\%) than in early abandoners $(20 \%)$, who had actually received the treatment to some extent.

Among the early abandoners, the main reasons for stopping AIT were insufficient perceived efficacy (39\% on average, ranging from $16 \%$ in France to $68 \%$ in Germany), financial expense (39\%), practical constraints (32\% on average, ranging from $16 \%$ in Germany to $56 \%$ in France), no perceived change in symptoms (25\%), and receipt of discouraging information about AIT (9 \%, primarily from relatives and the media). Among the non-starters, the main reasons for not starting were financial expense (34\%), practical constraints (31\%), insufficient perceived benefits $(25 \%)$ and fear of adverse events (22\%).

\section{The participant's perception of the information on allergy} and AIT provided by the physician

Overall, $27 \%$ of the participants had not been told that respiratory allergy was a chronic condition, $36 \%$ had not been told that respiratory allergy was an immune disorder and $24 \%$ had been told that respiratory allergies can worsen. A small but non-negligible proportion of participants $(7 \%)$ had not been told about any of these aspects (with as many as $16 \%$ in the USA).

Although $91 \%$ of participants had been told how AIT is thought to work, only $34 \%$ could recall being told about the overall duration of AIT (2.7 years, on average, according to the participants who recollected hearing this information) and only $66 \%$ could recall being informed about safety (ranging from $45 \%$ in France to $80 \%$ in the USA and in Germany). Thirty-three percent of the participants (ranging from $22 \%$ in Germany to $40 \%$ in France to) stated that they were not asked about their treatment preferences. 
Table 2 Characteristics of the survey population

\begin{tabular}{|c|c|c|c|c|c|c|}
\hline & France & Germany & Spain & USA & Russia & All countries \\
\hline \multicolumn{7}{|c|}{ Number of patients (M/F): } \\
\hline total population & $57(18 / 39)$ & $51(20 / 31)$ & $52(31 / 21)$ & $51(16 / 35)$ & $50(15 / 35)$ & $261(100 / 161)$ \\
\hline "early abandoners" & $25(11 / 14)$ & $25(15 / 10)$ & $26(19 / 7)$ & $26(8 / 18)$ & $25(9 / 16)$ & $134(62 / 72)$ \\
\hline "non-starters" & $32(7 / 25)$ & $26(5 / 21)$ & $26(12 / 14)$ & $25(8 / 17)$ & $25(6 / 19)$ & $127(38 / 89)$ \\
\hline \multicolumn{7}{|c|}{ Mean [range] age (years): } \\
\hline total population & $41[19-72]$ & $40.8[18-70]$ & $35.3[22-61]$ & $42[22-70]$ & $37.0[18-60]$ & 39.4 [18-72] \\
\hline "early abandoners" & 37.9 [19-72] & $35.5[18-67]$ & $35.3[23-59]$ & $39.5[26-58]$ & $37.4[18-60]$ & $37.1[18-72]$ \\
\hline "non-starters" & $43.2[21-63]$ & $46[20-70]$ & $35.4[22-61]$ & 44.5 [22-70] & $36.7[18-53]$ & $41.4[18-70]$ \\
\hline \multicolumn{7}{|c|}{ Mean [range] time since allergy } \\
\hline onset (years): & & & & & & 14.5 \\
\hline total population & $11.0[1-33]$ & $12.0[1-45]$ & $13.5[1-40]$ & $18.8[2-64]$ & $12.5[2-33]$ & [1-64]. \\
\hline "early abandoners" & $9.9[2-30]$ & $8.3[1-45]$ & $11.4[1-30]$ & $17.4[2-54]$ & $10.7[2-30]$ & $11.4[1-54]$ \\
\hline "non-starters" & $11.9[1-33]$ & $15.6[1-44]$ & $15.5[1-40]$ & $20.3[2-64]$ & $14.2[3-33]$ & $15.3[1-64]$ \\
\hline \multicolumn{7}{|l|}{ Stated allergies: } \\
\hline grass pollen & $78 \%$ & $84 \%$ & $58 \%$ & $96 \%$ & $68 \%$ & $77 \%$ \\
\hline house dust mite & $53 \%$ & $59 \%$ & $65 \%$ & $78 \%$ & $36 \%$ & $58 \%$ \\
\hline tree pollen & $67 \%$ & $45 \%$ & $52 \%$ & $90 \%$ & $40 \%$ & $59 \%$ \\
\hline animal dander & $40 \%$ & $35 \%$ & $46 \%$ & $67 \%$ & $38 \%$ & $45 \%$ \\
\hline other & $3 \%$ & $8 \%$ & $12 \%$ & $29 \%$ & $8 \%$ & $12 \%$ \\
\hline \multicolumn{7}{|c|}{ Moderate-to-severe impact of } \\
\hline \multicolumn{7}{|c|}{ allergy on personal life: } \\
\hline total population & $79 \%$ & $77 \%$ & $81 \%$ & $96 \%$ & $96 \%$ & $85 \%$ \\
\hline "early abandoners" & $82 \%$ & $65 \%$ & $81 \%$ & $92 \%$ & $96 \%$ & $83 \%$ \\
\hline "non-starters" & $76 \%$ & $88 \%$ & $81 \%$ & $100 \%$ & $96 \%$ & $88 \%$ \\
\hline \multicolumn{7}{|c|}{ Moderate-to-severe impact of } \\
\hline \multicolumn{7}{|c|}{ allergy on professional life } \\
\hline total population & $65 \%$ & $63 \%$ & $70 \%$ & $76 \%$ & $88 \%$ & $73 \%$ \\
\hline "early abandoners" & $60 \%$ & $38 \%$ & $77 \%$ & $76 \%$ & $84 \%$ & $71 \%$ \\
\hline "non-starters" & $69 \%$ & $88 \%$ & $62 \%$ & $77 \%$ & $92 \%$ & $75 \%$ \\
\hline \multicolumn{7}{|c|}{ Patient consulting a specialist as } \\
\hline \multicolumn{7}{|c|}{ their main physician: } \\
\hline total population & $54 \%$ & $69 \%$ & $68 \%$ & $44 \%$ & $62 \%$ & $59 \%$ \\
\hline "early abandoners" & $36 \%$ & $54 \%$ & $58 \%$ & $30 \%$ & $60 \%$ & $45 \%$ \\
\hline "non-starters" & $68 \%$ & $84 \%$ & $77 \%$ & $58 \%$ & $64 \%$ & $74 \%$ \\
\hline
\end{tabular}

When asked to spontaneously recall the potential benefits of AIT as presented by their physician, $26 \%$ mentioned nasal and ocular symptom relief, $22 \%$ reported a long-term solution, $16 \%$ reported an improvement in quality of life and $5 \%$ mentioned a reduction in medication use. However, when prompted, $76 \%$ of the participants reported that the physician did indeed mention symptom relief, with $51 \%$ for a long-term solution, $72 \%$ for an improvement in quality of life, and $52 \%$ for a reduction in medication use.

When asked to spontaneously recall the potential disadvantages of AIT, $22 \%$ mentioned the overall duration of treatment, $12 \%$ mentioned lack of perceived efficacy, and $8 \%$ mentioned adverse events. Strikingly, $14 \%$ of the participants reported that they did not spontaneously recall any disadvantages being mentioned. According to the participants, only $34 \%$ of the physicians mentioned the total treatment duration.

The participants had been asked to state their willingness to undergo AIT on the basis of the physician's presentation of allergy and AIT. On a numeric scale from 0 (least willing) to 10 (most willing), the mean score for the overall survey population was 5.7 (early 
Assessed for eligibility

( $\mathrm{n}=32,058$ worldwide; 9,995 in France, 7,573 in Germany,

5,213 in Spain, 9,217 in the USA, not determined but $>60$ in Russia)

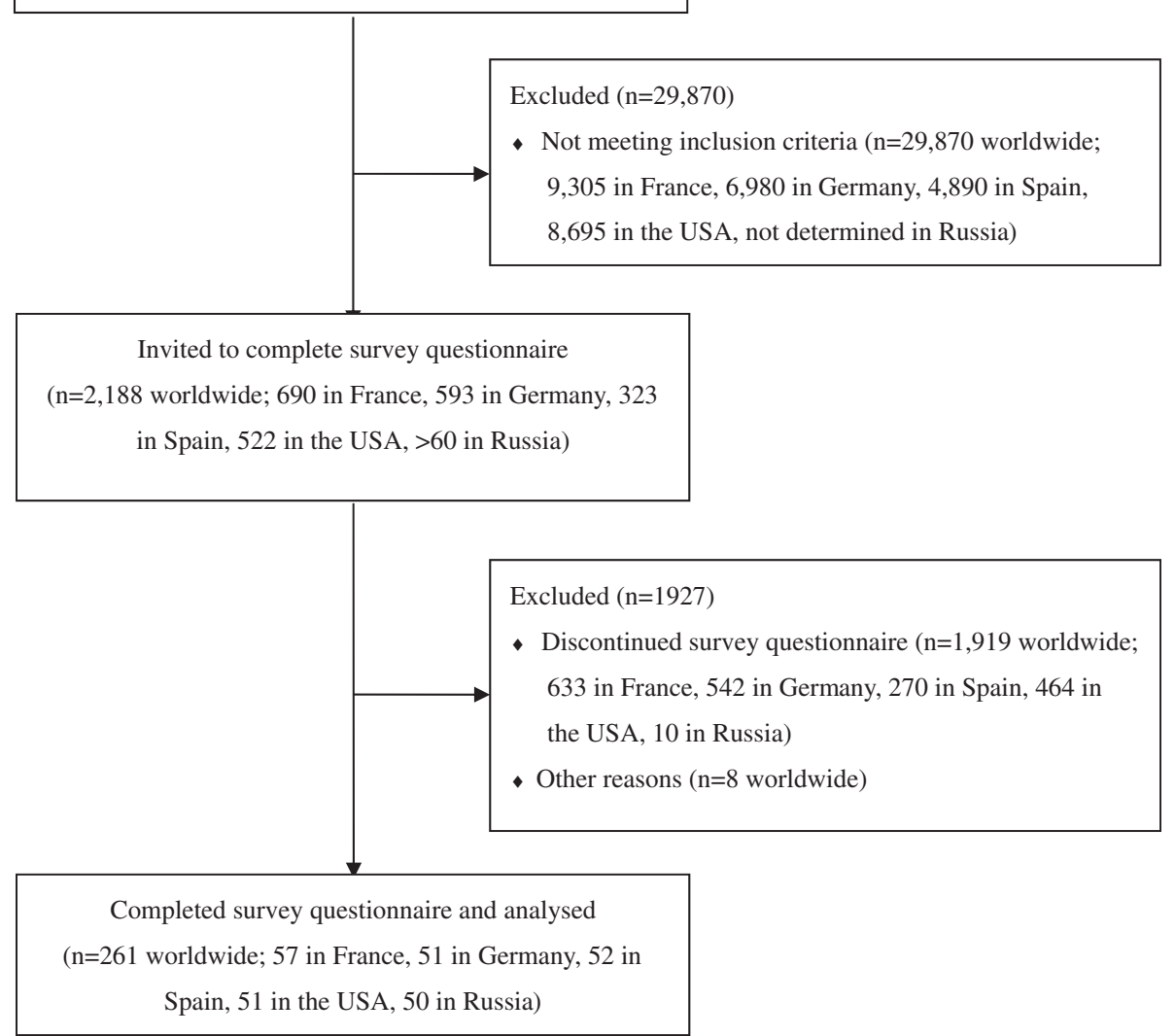

Fig. 1 The study flow chart

abandoners: 6.2; non-starters: 5.1 ). There were slight differences in the mean score from one country to another for early abandoners (France: 6.4; Germany: 5.6; Spain: 7.6; USA: 6.2; Russia: 5.0) and for non-starters (France: 4.7; Germany: 4.9; Spain: 6.7; USA: 4.4; Russia: 5.0).
The participant's perception of the new communication template on allergy and AIT

Participants considered the new communication template on allergy and AIT (Table 3) to be clear (92\%), convincing $(75 \%)$ and reassuring (89\%), and they felt

Table 3 Characteristics of the prescribed AIT preparations and administration regimens

\begin{tabular}{|c|c|c|c|c|c|c|}
\hline & France & Germany & Spain & USA & Russia & Overall study population \\
\hline \multicolumn{7}{|c|}{ Proportion of patients unaware of the type of allergen being administered: } \\
\hline total population & $46 \%$ & $18 \%$ & $29 \%$ & $20 \%$ & $24 \%$ & $28 \%$ \\
\hline "early abandoners" & $40 \%$ & $8 \%$ & $19 \%$ & $23 \%$ & $12 \%$ & $20 \%$ \\
\hline "non-starters" & $50 \%$ & $27 \%$ & $38 \%$ & $16 \%$ & $36 \%$ & $34 \%$ \\
\hline \multicolumn{7}{|l|}{ Type of AIT formulation prescribed in the overall population: } \\
\hline SCIT & $38 \%$ & $61 \%$ & $33 \%$ & $88 \%$ & $82 \%$ & $60 \%$ \\
\hline SLIT drops & $31 \%$ & $10 \%$ & $21 \%$ & $8 \%$ & $4 \%$ & $15 \%$ \\
\hline SLIT tablets & $24 \%$ & $27 \%$ & $46 \%$ & $4 \%$ & $14 \%$ & $23 \%$ \\
\hline unspecified & $7 \%$ & $2 \%$ & $0 \%$ & $0 \%$ & $0 \%$ & $2 \%$ \\
\hline Proportion of patients prescribed with a continuous regimen & $38 \%$ & $27 \%$ & $38 \%$ & $76 \%$ & $28 \%$ & $41 \%$ \\
\hline
\end{tabular}


better informed as a result ( $80 \%)$. The new communication template was considered to be more detailed (65\%), easier to understand (56\%) and more convincing (65\%) than the information that participants had received in their physician's office (Fig. 2). Only $8 \%$ of the participants felt that information about AIT given by the physician was absent from the communication template. In contrast, $57 \%$ considered that information given by the communication template was not included in the physician's presentation. Ninety-two percent of the participants considered that the way AIT works was clearly explained in the communication template.

After viewing the parts of the new communication template on allergy, $57 \%$ of the participants spontaneously recalled that allergy is an immune disorder. Few participants $(4 \%)$ participants spontaneously recalled that AR can progress to asthma. prompted by the onscreen appearance of closed "yes"/"no" questions on this topic, $84 \%$ of the participants stated that allergy is an immune disorder, and $72 \%$ stated that AR can progress to asthma. After viewing the parts of the communication template on AIT, a minority of participants spontaneously recalled that AIT can improve quality of life (31\%), that AIT is effective over the long term (29\%) and that there are several possible administration routes (30 \%). However, when subsequently prompted with closed "yes"/"no" questions on this topic, the majority of the participants stated that AIT has long-term efficacy (72 \%), can reduce medication use $(70 \%)$, relieve both nasal and ocular symptoms (65\%), "rebalances" the immune system ( $54 \%$ ) and can be administered by several different routes (51\%).

After having viewed the communication template, $89 \%$ of the participants stated that AIT might meet their needs, and $76 \%$ of participants stated that they would have been more likely to start or continue an AIT treatment if their physician had used the new communication template. Furthermore, $68 \%$ of participants stated that they were currently willing to start/resume AIT treatment. When asked to quantify their willingness to start or resume a course of AIT, the mean score was 7.1 out of 10 (i.e. an increase of 1.5 points over the score rated before presentation of the communication template). To examine the participants' "before vs. after" data in more detail, we grouped the individual scores into classes: a score of 8 to 10 was defined as "very willing", with 5 to 7 defined as "willing", 3 or 4 as "unwilling", 1 or 2 as "very unwilling" and 0 as "extremely unwilling" (Fig. 3). The proportion of participants who were either "willing" or "very willing" to start or resume a course of AIT increased markedly after viewing the communication template in all of the countries other than Spain (Fig. 3). The most marked increase in willingness was recorded in Russia, where the proportion of participants either "willing" or "very willing" to start or resume a course of AIT was $28 \%$ before viewing the communication template and $74 \%$ afterwards.

\section{Discussion}

The quantifiable components of medication adherence (initiation, implementation, and discontinuation/persistence) are variously affected by many interacting factors, including the patient's preferences and views on treatments and personal needs, adequate knowledge of the disease, perceived health risks, costs, health literacy, concerns about disease worsening and complications, expectations about treatment outcomes and concerns about side effects [23-31].

In the present multinational, Internet-based survey, we focused on the participant's knowledge of their respiratory allergic disease and AIT and the relationship between this knowledge and willingness to start or resume this type of therapy. The survey was designed to assess participants' understanding of allergy and their acceptance of allergen immunotherapy on the basis of information provided by their physician at the time of prescription and information in a new communication template viewed some months later. In contrast, the survey was

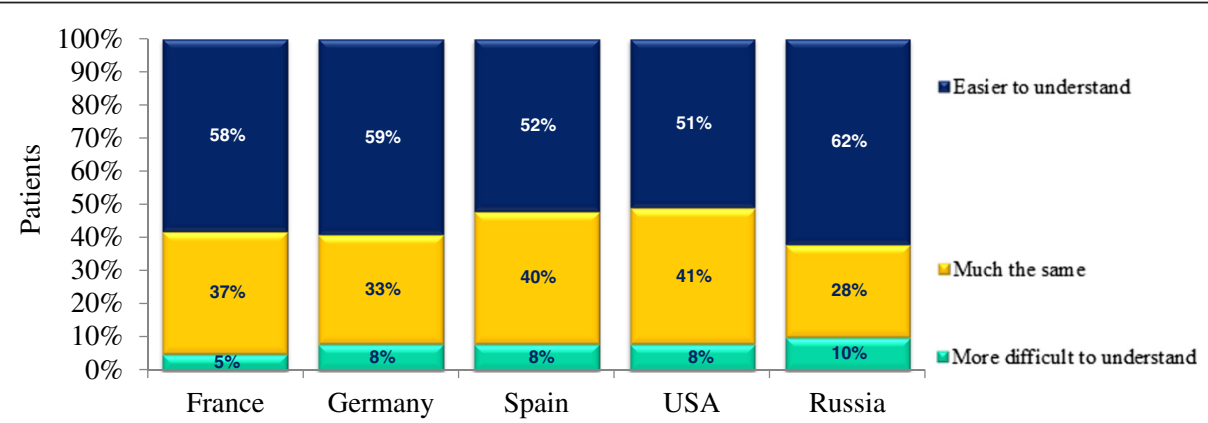

Fig. 2 Understanding of the new communication template. In each country, participants were asked "How does this new presentation of AlT [the new communication template] compare with that given by your physician?". The possible answers were "Easier to understand", "More difficult to understand" and "Much the same?" 


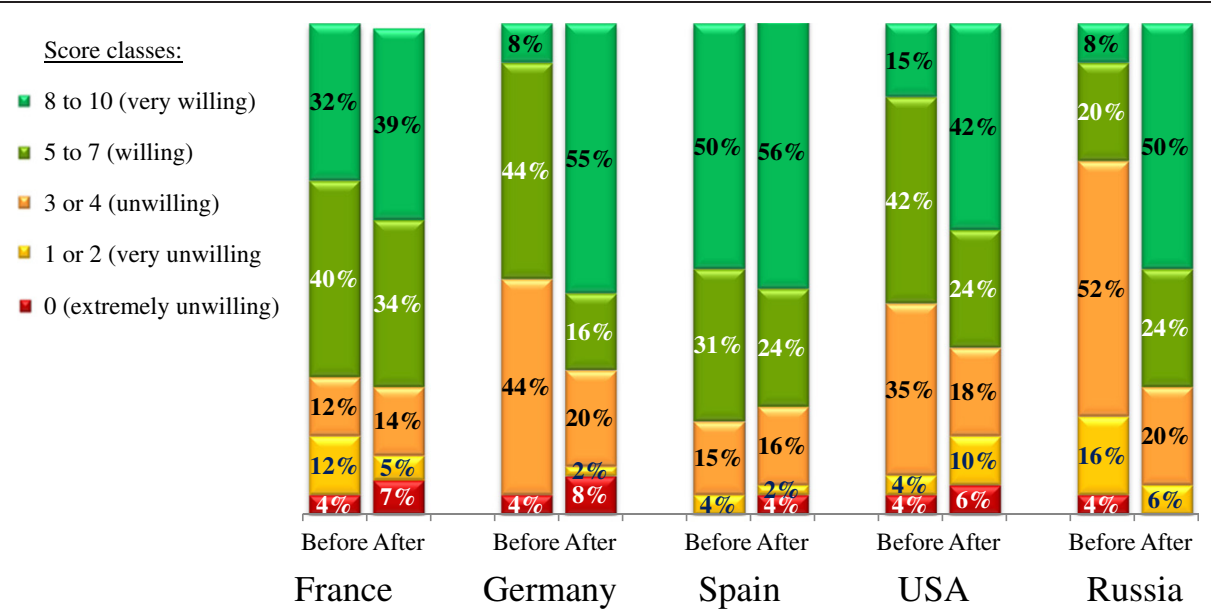

Fig. 3 Willingness to initiate or resume AIT. In each country, participants were asked to state their willingness to initiate or resume AIT before and then after presentation of the new information template (from 0 , least willing, to 10, most willing). The results are presented by score class

not designed to (i) compare "early abandoners" with "non-starters", (ii) compare dissatisfied participants with satisfied participants or, more generally, (iii) determine which factors may be associated with unwillingness to initiate or continue AIT.

The survey population comprised patients with moderate to severe symptoms and who had been suffering from allergies for many years (an average of 14.5 years prior to inclusion in the survey). The results of the present Internet-based survey show clearly that the participants were either not optimally informed about allergic disease and AIT by their physician, or had forgotten some of the key information given since their consultation with the physician. This lack of knowledge was most worryingly evidenced by the fact that $28 \%$ of the participants did not know with which allergen they were being treated, which can influence the perception of efficacy according to some allergens. Furthermore, $27 \%$ of participants did not know that allergy is a chronic disease and $24 \%$ were unaware of the progressive nature of allergy. Hence, lack of knowledge may have prompted the "early abandoners" to discontinue AIT. The main reasons for discontinuation by the "early abandoners" were lack of perceived efficacy (39\%) and cost (39\%). In a review on adherence to AIT, Senna et al. considered that the main reasons for discontinuation (i.e. lack of persistence) were inconvenience, a lack of efficacy, costs and loss of working hours, and side effects [23]. In studies of real-life practice with infrequent consultations, lack of perceived efficacy may be an important driver of poor adherence. Although AIT starts to relieve symptoms within a few weeks or months [20-22], patients may have unrealistic expectations of quick improvements in symptoms (such as those they may have experienced with antihistamines and nasal corticosteroids). We suggest that patients' adherence to AIT could be enhanced by more accurate presentation of this treatment modality to patients, making them better prepared for progressive (and thus less immediately visible) changes. This issue is also addressed in the recently published guideline on AIT by the German, Austrian and Swiss allergic societies, which provides a 'treatment information sheet' that informs the patient about practical aspects of AIT (such as expected effects, the type and duration of treatment, possible side effects and alternative treatments) [34]

Conversely, the high levels of adherence found in clinical trials result (in part) from regular monitoring of the enrolled patients [28], and so non-adherence in these trials depends more on the patient's monitoring and motivation than on his/her perception of inefficacy or other causes. Hence, as in clinical trials, a solid partnership between the patient and the physician throughout the course of AIT is necessary for treatment success routine clinical practice. We suggest that the physician should monitor changes over time in efficacy and outcomes, in order to improve levels of dialogue and boost the patient's motivation.

The present survey had a number of limitations, many of which are inherent to observational, self-reported, Internet-based surveys. The small sample sizes prevented statistical analysis, and so assessment of any significant differences in profile between "non-starters" and "early abandoners" was not possible. The small number of participants in each country and lack of knowledge of clinical profiles prevented us from applying statistical tests and comparing one country with another. Given that participants had to fill out a screening questionnaire to check that the selection criteria were met, it may be that only highly motivated participants completed this stage and thus did not represent a typical patient population (i.e. selection bias). The data were anonymous and self-reported over the Internet, 
which may have introduced bias. Some of the clinical details (such as the nature of the allergy-inducing allergens in a given participant) may not have been recently validated by a physician. The participants were not necessarily AIT-naïve, and may have initiated (and perhaps completed) a course of AIT previously. However, all participants considered for eligibility had physiciandiagnosed AR. Furthermore, the participants' selfassessments of symptom severity and impact on quality of life were not recorded with standardized, validated tools. The survey may have suffered from recall bias (especially concerning the information presented by the physician), since the participants were questioned up to 12 months after the consultation in which AIT was recommended. It is possible that participants had been well informed at the consultation but had since forgotten part of the information; this may have artificially improved the participants' perception of the new communication template. The "baseline" levels of information about AIT and allergy doubtless vary from one country to another and from one physician or specialty to another. Furthermore, there were doubtless marked differences in the extent to which and the way in which the physicians provided the participants with information (i.e. conversation, leaflets, Internet documents, etc.). In the US, for example, patients receiving SCIT at a health care facility other than the prescribing office read and approve a detailed information and consent letter [35]. In contrast, the new communication template was always viewed on the screen of a computer or other Internet-connected device. Furthermore, the study questionnaire was developed by the authors by consensus and was not extensively tested or psychometrically validated prior to use in the study. Lastly, we assessed acceptance of and motivation for AIT, rather than quantifiable components of adherence per se.

In the present Internet-based survey, viewing of a communication template was associated with markedly better recall of the features of allergy and AIT when the survey participants were prompted by the on-screen appearance of closed "yes"/"no" questions on a given topic. In contrast, spontaneous recall of these features was suboptimal. In clinical practice, however, the communication template would be presented and discussed with the physician, and so better spontaneous recall could be expected in an interactive context. Use of the present communication template revealed the need for (and value of) simple, objective, defined information on allergy and AIT.

\section{Conclusion}

For optimal clinical effectiveness, a course of AIT should be completed as part of a mutually agreed "moral contract" between the patient and his/her physician, where both partners "buy in" to the disease management strategy and each has duties and obligations in maintaining or improving health. The way in which the physician presents AIT to his/her patient is crucial in (i) providing accurate information for decision-making and (ii) increasing levels of commitment and adherence to therapy.

We found that after consulting the physician treating their allergy, many survey participants did not receive or retain important information about their allergic disease and AIT-including items that would probably have increased their degree of willingness to initiate or continue AIT. After having viewed a new information template on line, survey participants with allergies felt better informed and stated that they were more likely to initiate or resume AIT. However, the present survey's limitations (a small sample size, a lack of detailed knowledge of clinical profiles, possible selection bias, self-reporting of allergy status, and a lack of standardized assessments of symptom severity and quality of life) mean that the relationship between the new information template and actual adherence to AIT in clinical practice must be tested in a controlled study.

\section{Additional file}

Additional file 1: The survey questionnaire.

\section{Abbreviations}

AIT: Allergen immunotherapy; AR: Allergic rhinitis; IgE: Immunoglobulin E; SCIT: Subcutaneous allergen immunotherapy; SLIT: Sublingual allergen immunotherapy.

\section{Competing interests}

Moises A. Calderon has received consulting fees, honoraria for lectures and/ or research funding from ALK, Stallergenes, Merck, Allergopharma and HAL. Linda Cox has received consulting fees from Stallergenes and is a past President of the American Academy of Allergy, Asthma \& Immunology. Thomas B. Casale has received consulting fees from Stallergenes and has been an investigator on grants awarded to Creighton University by Stallergenes and Schering-Plough-MSD. Hans-Jørgen Malling has received consulting fees, honoraria for lectures and/or research funding from ALK-Abelló, Stallergenes, Biomay and Anergis. Pascal Demoly is a consultant and a speaker for Stallergenes, Circassia, ALK and Chiesi and was a speaker for Merck, Astra Zeneca, Pierre Fabre Médicaments, Menarini, Allergopharma and GlaxoSmithKline in 2010-2014. Oliver Pfaar (OP) has received research grants for his institution from ALK Abelló (Germany/Denmark),Allergopharma (Germany), Stallergenes (Germany/France), HAL Allergy (Germany/the Netherlands), Artu Biologicals (the Netherlands), Allergy Therapeutics/Bencard (UK/Germany), Hartington (Spain), Lofarma (Italy), Novartis/Leti (Germany/Spain), GlaxoSmithKline (UK/Germany), Essex Pharma (Germany), Cytos (Switzerland), Curalogic (Denmark), Roxall (Germany), Biomay (Austria), Thermo Fisher (Germany), Circassia (UK), European Union (FP-7 Health-2013 Innovation 1), Biotech Tools s.a. (Belgium), and Meda Pharma GmbH (Germany); and/or he has served as an advisor and on speakers' bureaus for some of the aforementioned companies. OP has received travel grants from HAL Allergy (the Netherlands/ Germany) and Allergopharma (Germany), and he is a consultant for Bencard (Germany), HAL Allergy (the Netherlands), Novartis/Leti (Germany), Meda (Germany), ALK-Abelló (Germany/Denmark), Allergopharma (Germany), Biotech Tools s.a. (Belgium), GfK Bridgehead (UK), Navigant Consulting (USA), Sanofi (USA), Guidepoint Global Advisors (USA), Thermo Fisher (Germany) and Stallergenes (Germany/France); he is Scientific Board Member of Mobile Chamber Experts 
(MCX), a GA2LEN Partner. OP is the current chairman of the Immunotherapy Interest Group (IT IG) of the European Academy of Allergy and Clinical Immunology (EAACI) and is the secretary of the ENT section of Deutsche Gesellschaft für Allergologie und Klinische Immunologie (DGAKI). He has received grants for the "Spezifische Immuntherapie"-award 2014 and the "Nachwuchsförderpreis"award 2010 of the DGAKI. He is co-editor and an author of the textbook "Allergien bei Kindern und Jugendlichen" (publisher: Schattauer-Verlag, Germany) and author of different chapters of "Allergologie- Handbuch" (publisher: Schattauer-Verlag, Germany) and has received payment for development of educational presentations from GlaxoSmithKline (Germany), Bencard (Germany), and Novartis (Germany). The other authors declare no competing interests.

\section{Authors' contributions}

MC and PD conceived the study. All authors (MC, LC, TC, RM, OP, HJM, JS, MK and PD) participated in its coordination and helped to draft the manuscript. All authors read and approved the final manuscript.

\section{Acknowledgements}

We thank David Fraser D. Phil. (Biotech Communication SARL, Damery, France) for medical writing support on behalf of Stallergenes SA. The present work was developed with an unrestricted grant from Stallergenes SA and ALK-Abelló.

\section{Author details}

'Section of Allergy and Clinical Immunology, Imperial College London National Heart \& Lung Institute, Royal Brompton Hospital, Dovehouse Street, London, United Kingdom. ${ }^{2}$ Nova Southeastern University, Davie, FL, USA. ${ }^{3}$ Internal Medicine, Morsani College of Medicine, University of South Florida, Tampa, FL, USA. ${ }^{4}$ Universitätsklinikum Köln, Universität zu Köln, Köln, Germany. ${ }^{5}$ Center for Rhinology and Allergology, Wiesbaden, Germany. ${ }^{6}$ Department of Otorhinolaryngology, Head and Neck Surgery, Universitätsmedizin Mannheim, Medical Faculty Mannheim, Heidelberg University, Mannheim, Germany. ${ }^{7}$ Allergy Clinic, Danish AllergyCenter, Dermato-Allergological Department, Gentofte University Hospital, Copenhagen, Denmark. ${ }^{8}$ Allergy Department, Fundación Jiménez Díaz, Madrid, Spain. ${ }^{9}$ NRC Institute of Immunology FMBA, Moscow, Russian Federation. ${ }^{10}$ Department of Pulmonology - Division of Allergy, Hôpital Arnaud de Villeneuve, University Hospital of Montpellier, Montpellier, France. ${ }^{11}$ Sorbonne Universités, UPMC Paris 06, UMR-S 1136, IPLESP, Equipe EPAR, Paris, France.

\section{Received: 20 February 2015 Accepted: 13 May 2015}

\section{Published online: 22 May 2015}

\section{References}

1. Bousquet J, Khaltaev N, Cruz AA, Denburg J, Fokkens WJ, Togias A, et al. Allergic rhinitis and its impact on asthma (ARIA) 2008 update (in collaboration with the world health organization, GA2LEN and AllerGen). Allergy. 2008;63:S8-S160.

2. Brozek JL, Bousquet J, Baena-Cagnani CE, Bonini S, Canonica GW, Casale TB, et al. Global allergy and asthma European network; grading of recommendations assessment, development and evaluation working group: allergic rhinitis and its impact on asthma (ARIA) guidelines: 2010 revision. J Allergy Clin Immunol. 2010;126:466-76.

3. Wallace DV, Dykewicz MS, Bernstein DI, Blessing-Moore J, Cox L, Khan DA, et al. Tilles SA; joint task force on practice; American academy of allergy; asthma \& immunology; American college of allergy; asthma and immunology; joint council of allergy, asthma and immunology: the diagnosis and management of rhinitis: an updated practice parameter. J Allergy Clin Immunol. 2008;122(2 Suppl):S1-S84.

4. Katelaris $\mathrm{CH}$, Lee BW, Potter PC, Maspero JF, Cingi C, Lopatin A, et al. Prevalence and diversity of allergic rhinitis in regions of the world beyond Europe and north America. Clin Exp Allergy. 2012;42:186-207.

5. Chuchalin AG, Khaltaev N, Antonov NS, Galkin DV, Manakov LG, Antonini $P$, et al. Chronic respiratory diseases and risk factors in 12 regions of the Russian federation. Int J Chron Obstruct Pulmon Dis. 2014;9:963-74.

6. Shaaban R, Zureik M, Soussan D, Neukirch C, Heinrich J, Sunyer J, et al. Rhinitis and onset of asthma: a longitudinal population-based study. Lancet. 2008;372:1049-57.
7. Valovirta E, Myrseth SE, Palkonen S. The voice of the patients: allergic rhinitis is not a trivial disease. Curr Opin Allergy Clin Immunol. 2008;8:1-9.

8. Meltzer EO, Bukstein DA. The economic impact of allergic rhinitis and current guidelines for treatment. Ann Allergy Asthma Immunol. 2011;106:S12-6.

9. Hellings PW, Fokkens WJ, Akdis C, Bachert C, Cingi C. Uncontrolled allergic rhinitis and chronic rhinosinusitis: where do we stand today? Allergy. 2013;68:1-7.

10. Alvarez-Cuesta E, Bousquet J, Canonica GW, Durham SR, Malling HJ. Valovirta E; EAACl, immunotherapy task force: standards for practical allergen-specific immunotherapy. Allergy. 2006;61 Suppl 82:1-20.

11. Canonica GW, Bousquet J, Casale T, Lockey RF, Baena-Cagnani CE, Pawankar $\mathrm{R}$, et al. Sub-lingual immunotherapy: world allergy organization position paper 2009. Allergy. 2009;64 Suppl 91:1-59.

12. Canonica GW, Cox L, Pawankar R, Baena-Cagnani CE, Blaiss M, Bonini S, et al. World Allergy Organization position paper 2013 update. World Allergy Organ J. 2014;7:6. doi:10.1186/1939-4551-7-6.

13. Cox L, Nelson H, Lockey R, Calabria C, Chacko T, Finegold I, et al. Allergen immunotherapy: a practice parameter third update. J Allergy Clin Immunol. 2011;127(1 Suppl):S1-S55.

14. Burks AW, Calderon MA, Casale T, Cox L, Demoly P, Jutel M, et al. Update on allergy immunotherapy: American academy of allergy, asthma \& immunology/European academy of allergy and clinical immunology/PRACTALL consensus report. J Allergy Clin Immunol. 2013;131:1288-96.

15. Viswanathan RK, Busse WW. Allergen immunotherapy in allergic respiratory diseases: from mechanisms to meta-analyses. Chest. 2012;141:1303-14.

16. Eifan AO, Shamji MH, Durham SR. Long-term clinical and immunological effects of allergen immunotherapy. Curr Opin Allergy Clin Immunol. 2011;11:586-93.

17. Fujita $H$, Soyka MB, Akdis M, Akdis CA. Mechanisms of allergen-specific immunotherapy. Clin Transl Allergy. 2012;2:2.

18. Meadows A, Kaambwa B, Novielli N, Huissoon A, Fry-Smith A, Meads C, et al. A systematic review and economic evaluation of subcutaneous and sublingual allergen immunotherapy in adults and children with seasonal allergic rhinitis. Health Technol Assess. 2013;17:1-322. vi, xi-xiv.

19. Hankin CS, Cox L. Allergy immunotherapy: what is the evidence for cost saving? Curr Opin Allergy Clin Immunol. 2014;14:363-70.

20. Calderon MA, Birk AO, Andersen JS, Durham SR. Prolonged preseasonal treatment phase with grazax sublingual immunotherapy increases clinical efficacy. Allergy. 2007;62:958-61.

21. Francis JN, James LK, Paraskevopoulos G, Wong C, Calderon MA, Durham SR, et al. Grass pollen immunotherapy: IL-10 induction and suppression of late responses precedes lgG4 inhibitory antibody activity. J Allergy Clin Immunol. 2008;121:1120-5. doi:10.1016/j.jaci.2008.01.072.

22. Horak F, Zieglmayer $P$, Zieglmayer $R$, Lemell $P$, Devillier $P$, Montagut $A$, et al. Early onset of action of a 5-grass-pollen 300-IR sublingual immunotherapy tablet evaluated in an allergen challenge chamber. J Allergy Clin Immunol. 2009;124:471-7.

23. Senna G, Ridolo E, Calderon M, Lombardi C, Canonica GW, Passalacqua G. Evidence of adherence to allergen-specific immunotherapy. Curr Opin Allergy Clin Immunol. 2009;9:544-8.

24. Hankin CS, Lockey RF. Patient characteristics associated with allergen immunotherapy initiation and adherence. J Allergy Clin Immunol. 2011;127:46-8.

25. Vrijens B, De Geest S, Hughes DA, Przemyslaw K, Demonceau J, Ruppar T, et al. $A B C$ project team: a new taxonomy for describing and defining adherence to medications. Br J Clin Pharmacol. 2012;73:691-705. doi:10.1111/j.1365-2125.2012.04167.x.

26. Apter AJ, Wan F, Reisine S, Bender B, Rand C, Bogen DK, et al. The association of health literacy with adherence and outcomes in moderate-severe asthma. J Allergy Clin Immunol. 2013;132:321-7.

27. Reisacher WR, Visaya JM. Patient adherence to allergy immunotherapy. Curr Opin Otolaryngol Head Neck Surg. 2013;21:256-62.

28. Antico A. Long-term-adherence to sublingual therapy: literature review and suggestions for management strategies based on Patients' needs and preferences. Clin Exp Allergy. 2014;44:1314-26. doi:10.1111/cea.12362.

29. Skoner DP, Blaiss MS, Dykewicz MS, Smith N, Leatherman B, Bielory L, et al. The allergies, immunotherapy, and RhinoconjunctivitiS (AIRS) survey: patients' experience with allergen immunotherapy. Allergy Asthma Proc. 2014;35:219-26. 
30. Anolik R, Schwartz AM, Sajjan S, Allen-Ramey F. Patient initiation and persistence with allergen immunotherapy. Ann Allergy Asthma Immunol. 2014;113:101-7.

31. Kiel MA, Röder E, van Gerth WR, Al MJ, Hop WC, Rutten-van Mölken MP. Real-life compliance and persistence among users of subcutaneous and sublingual allergen immunotherapy. J Allergy Clin Immunol. 2013;132:353-60 e2.. doi:10.1016/j.jaci.2013.03.013.

32. Wild D, Grove A, Martin M, Eremenco S, McElroy S, Verjee-Lorenz A. ISPOR task force for translation and cultural adaptation: principles of good practice for the translation and cultural adaptation process for patient-reported outcomes (PRO) measures: report of the ISPOR task force for translation and cultural adaptation. Value Health. 2005;8:94-104.

33. Nair K, Dolovich L, Cassels A, McCormack J, Levine M, Gray J, et al. What patients want to know about their medications. Focus group study of patient and clinician perspectives. Can Fam Physician. 2002;48:104-10.

34. Pfaar O, Bachert C, Bufe A, Buhl R, Ebner C, Eng P, et al. Guideline on allergen-specific immunotherapy in IgE-mediated allergic diseases - S2k Guideline of the German Society for Allergology and Clinical Immunology (DGAKI), the Society for Pediatric Allergy and Environmental Medicine (GPA), the Medical Association of German Allergologists (AeDA), the Austrian Society for Allergy and Immunology (ÖGAl), the Swiss Society for Allergy and Immunology (SGAI), the German Society of Dermatology (DDG), the German Society of Oto-Rhino-Laryngology, Head and Neck Surgery (DGHNO-KHC), the German Society of Pediatrics and Adolescent Medicine (DGKJ), the Society for Pediatric Pneumology (GPP), the German Respiratory Society (DGP), the German Association of ENT Surgeons (BV-HNO), the Professional Federation of Paediatricians and Youth Doctors (BVKJ), the Federal Association of Pulmonologists (BDP) and the German Dermatologists Association (BVDD). Allergo J Int. 2014;23:282-319.

35. Position statement on the administration of immunotherapy outside of the prescribing allergist facility. Drugs and Anaphylaxis Committee of the American College of Allergy, Asthma and Immunology. Ann Allergy Asthma Immunol. 1998;81:101-2.

\section{Submit your next manuscript to BioMed Central and take full advantage of:}

- Convenient online submission

- Thorough peer review

- No space constraints or color figure charges

- Immediate publication on acceptance

- Inclusion in PubMed, CAS, Scopus and Google Scholar

- Research which is freely available for redistribution 